\title{
Usporedba metoda slikovne dijagnostike hernijacije intervertebralnog diska u pasa
}

\author{
T. Bureš*, H. Capak, B. Škrlin, D. Stanin, A. Kraljević, D. Nappo i \\ Z. Vrbanac
}

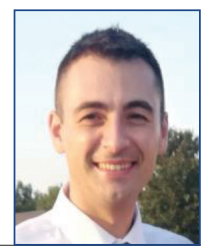

\section{Sažetak}

Hernijacija intervertebralnog diska jedna je od češćih bolesti međukralježničnog diska. Etiološki gledano, mnogi su uzroci ovoga stanja: degeneracije diska, traume, infekcije ili anatomske/razvojne anomalije. U dijagnostici hernijacije moguće je služiti se raznim metodama slikovne dijagnostike; najčešće nativnom rendgenografijom, mijelografijom, kompjuteriziranom tomografijom ili magnetnom rezonancijom. Prema dostupnim istraživanjima, najpouzdanija metoda pokazala se magnetna rezonancija koja omogućuje sigurnu dijagnostiku i lokalizaciju u $100 \%$ slučajeva dok su za ostale metode postotci uspješnosti detekcije

niži. Treba napomenuti da je korištenje određene metode slikovne dijagnostike $\mathrm{u}$ lokalizaciji i lateralizaciji mjesta hernijacije intervertebralnog diska u svakodnevnoj praksi najčešće ovisno o financijskim mogućnostima vlasnika, dostupnosti određene metode i hitnosti stanja. Shodno tome, rezultati pretraga variraju, kao i točnost lokalizacije hernijacije. Cilj je ovoga preglednog rada prikazati specifičnosti hernijacije intervertebralnog diska te mogućnosti dijagnostike slikovnim metodama raspoloživima u svakodnevnoj veterinarskoj praksi.

Ključne riječi: slikovna dijagnostika, intervertebralni disk, hernijacija, pas

\section{Uvod}

Hernijacija intervertebralnog diska jedna je od čestih bolesti međukralježničnog diska. Etiološki gledano, mnogi uzroci dovode do ovoga stanja: degeneracije diska, traume, infekcije ili anatomske/

razvojne anomalije. Postoji više podjela hernijacija diska no najčešće korištena je ona koju je uveo Hansen 50 -ih godina prošlog stoljeća. U dijagnostici hernijacije služi se raznim metodama slikovne dija-

Tomislav BUREŠ* ${ }^{*}$ dr. med. vet., asistent, (dopisni autor, e-mail: tbures@vef.hr), dr. sc. Hrvoje CAPAK, dr. med. vet., docent, Branimir ŠKRLIN, dr. med. vet., stručni suradnik, Dino STANIN, dr. med. vet., stručni suradnik, Anita KRALJEVIĆ, dr. med. vet., studentica posijediplomskog specijalističkog studija, Veterinarski fakultet Sveučilišta u Zagrebu, Hrvatska; Dario NAPPO, dr. med. vet., Istituto Veterinario di Novara - AniCura Italy Novara, Italija; dr. sc. Zoran VRBANAC, dr. med. vet., DECVSMR, DACVSMR, izvanredni profesor, Veterinarski fakultet Sveučilišta u Zagrebu, Hrvatska 
gnostike, a to uključuje: nativnu rendgenografiju, mijelografiju, kompjuteriziranu tomografiju ili magnetnu rezonanciju. U ovom preglednom članku bit će prikazana patologija i specifičnosti hernijacije intervertebralnog diska te mogućnosti raspoložive slikovne dijagnostike.

\section{Podjela hernijacija intervertebralnog diska}

Povijesno gledano, pojam hernijacije intervertebralnog diska prvi je put objašnjen još 1950-ih godina (Olson, 1951., Hansen, 1952.). Tada je Hansen uveo u veterinarsku medicinu nomenklaturu koja je početno klasificirala bolest $\mathrm{u}$ dvije kategorije: ekstruzije (tip I) i protruzije (tip II) međukralježničnog diska. Deset godina kasnije, Funkquist je predložila podijelu hernijacije tip I (ekstruzije) intervertebralnog diska u 3 podtipa $(1,2$ i 3) (Funkquist, 1962., 1970.). U slučaju ekstruzije intervertebralnog diska (tip I hernijaciji) radi se o potpunoj rupturi anulusa fibrosusa s izbacivanjem nucleus pulposusa međukralježničnog diska. Materijal ekstrudiranog diska, promatramo li na MR-u (magnetna rezonanca), amorfan je i može značajnije komprimirati
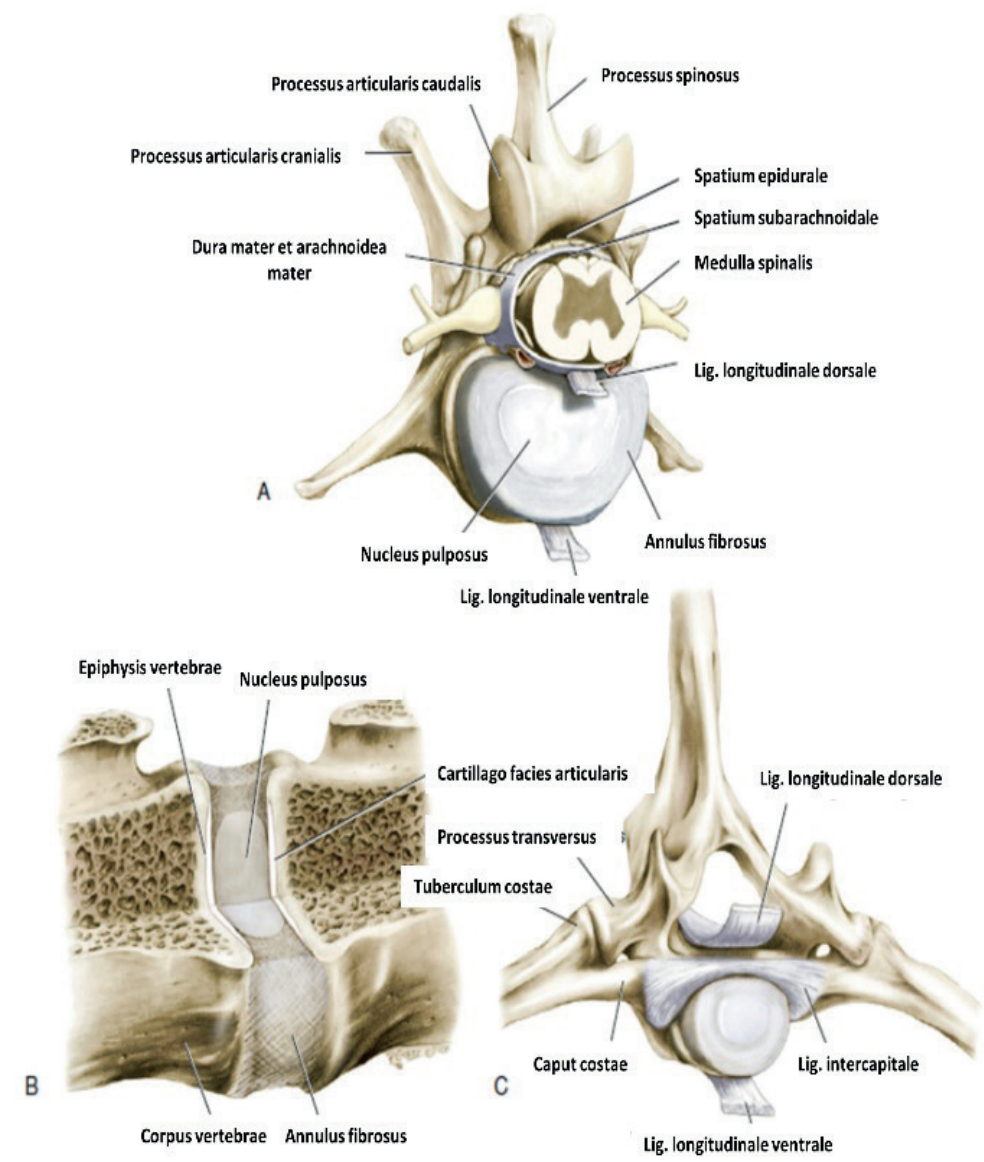

Slika 1. Prikaz anatomskih struktura kralježaka i pripadajućih ligamenata i diskova. (Preuzeto iz: Tobias, Johnston: Veterinary Surgery: Small Animal. Second Edition. 2018.) 
kralježničnu moždinu može biti fokalno vidljiv ili dispergiran. Pri tome, smještaj ekstrudiranog materijala ovisno o tome koliko će longitudinalni ligament biti u stanju očuvati medijanu ravninu tijela i kralježnice može biti medijan ili lateralan. Ekstrudirani se materijal može pomiješati i s krvlju iz oštećenog venskog sinusa $\mathrm{u}$ tom području. Ovaj oblik hernijacije je najčešće akutan u nastajanju, a predstavlja hondroidnu degeneraciju te najčešće zahvaća hondrodistrofične pasmina pasa. Radi boljeg razumijevanja, na slici 1 . su prikazane anatomske strukture kralježaka i pripadajućih ligamenata i diskova.

Najpregledniji, suvremeniji prikaz podjele hernijacija intervertebralnog diska iznijeli su u svom preglednom članku Heblinski i Schmökel (2018.). U slučaju Hansen tip I hernijacije, prema toj nomenklaturi razlikujemo više podtipova. Podtipovi 1 i 2 podrazumijevaju kraću disperziju ekstrudiranog materijala degeneriranog nucleus pulposusa u kanal kralježnične moždine, akutnog su do sporo progradirajućeg nastanka i najčešće se javljaju u hondrodistrofičnih pasmina pasa. Podtip 3 Hansen tipa I predstavlja dužu disperziju degeneriranog nucleus pulposusa koja se proteže preko tri ili više kralježaka (Funkquist, 1962.); najčešće je perakutnog do akutnog nastanka s težim simptomima te se u literaturi može naći i pod nazivom disk ekstruzije s ekstenzivnim krvarenjem (disk extrusion with extensive hemorrhage - DEEH). Nadalje, osim navedenih Hansen tip I oblika, unutar te grupe razlikujemo i Hansen tip 3, koji se u literaturi još naziva i akutna ekstruzija intervertebralnog diska, točnije, nedegeneriranog nucleus pulposusa. Perakutnog je nastanka, najčešće prouzročena traumom, često $\mathrm{s}$ težim simptomima. Unutar akutne ekstruzije intervertebralnog diska razlikujemo dva podtipa: akutnu nekompresivnu ekstruziju nucleus pulposusa (acute non-compressive nucleus pulposus extrusion - ANNPE) te intraduralnu/intramedularnu ekstruziju intervertebralnog diska (intradural/ intramedullary intervertebral disk extrusion - IIVDE). Kod akutne ekstruzije intervertebralnog diska u slučaju traume dolazi do rupture anulusa fibrosusa te viskozni nedegenerirani nucleus pulposus ekstrudira pod pritiskom posljedično prouzročeći i teže kliničke simptome. U slučaju ANNPE-a obično nema nucleus pulposus diska koji bi bio vidljiv tijekom dijagnostičke pretrage (npr. MRom) te se tada kirurška dekompresija smatra neučinkovitom. Hansen tip I tip 3 se još može pronaći i pod nazivom ekstruzije intervertebralnog diska velikom brzinom - malim volumenom (high velocity - low volume intervertebral disk extrusion) (Henke i sur., 2013.). U Hansen tip I se još može ubrojiti i podtip ekstruzije hidriranog nucleus pulposusa (hydrated nucleus pulposus extrusion HNPE) koji se najčešće dijagnosticira u cervikalnom području kralježnice, blago degeneriranog nucleus pulposus; akutnog je do perakutnog nastanka te je najčešće bezbolan oblik ekstruzije (Beltram i sur., 2012.). Osim navedenih, u Hansen tip I ubrajamo i ekstruziju intervertebralnog diska daleko-lateralno (far-lateral intervertebral disk extrusion), pri čemu dolazi do ekstruzije intervertebralnog diska lateralno i time se stvara kompresija na korijen živca i živac koji prolazi kroz foramen intervertebrale (Fadda i sur., 2013.). Nužno je naglasiti i moguć slučajan nalaz (na CT-u i MR-u) rijetke ekstruzije nucleus pulposusa intervertebralnog diska u tijelo kralješka kroz zonu rasta u obliku cistične lezije pri čemu dolazi do upale te posljedične apsorpcije kosti. Ovo se stanje u literaturi naziva i Schmorlov čvor (Gaschen i sur., 1995., Baltzer i sur., 2012.). Zbirni prikaz podjele hernijacije diska naveden je u Tabeli 1.

Hansen tip II podrazumijeva protruziju intervertebralnog diska, što je u stvari djelomična ruptura i dorzalno bujanje anulus fibrosus međukralježničnog 
diska. Ovaj tip hernijacije je najčešće po smještaju fokalan. Protrudirani materijal se smješta najčešće medijano ili ventrolateralno, materijal je gladak i zaobljen te $u$ ovom slučaju ne uvjetuje krvarenjem. Po tijeku je najčešće kroničan, predstavlja fibroidnu degeneraciju i zahvaća nehondrodistrofične pasmine pasa. Klinički znaci kod tipa II hernijacije su najčešće progresivni te se mogu javljati u obliku boli, ataksije, pareze i inkontinencije.

\section{Metode slikovne dijagnostike hernijacije intervertebralnog diska u pasa}

U današnje vrijeme $u$ veterinarskoj praksi dostupne su metode slikovne dijagnostike: nativna rendgenografija, mijelografija, kompjuterizirana tomografija (CT) i magnetna rezonanca (MR), različite specifičnosti i osjetljivosti za dijagnostiku hernijacije intervertebralnog diska.

Tabela 1. Prikaz podjele hernijacija intervertebralnog diska u pasa

\section{Tip hernijacije}

Hansen tip I

Podtipovi 1 i 2

Hansen tip I

Podtip 3

Dispergirana ekstruzija

intervertebralnog diska

Akutna nekompresivna ekstruzija nucleus pulposusa

(ANNPE), Traumatska ekstruzija intervertebralnog diska, Ekstruzija velikom brzinom - malim volumenom, Hansen 3

Intraduralna/intramedularna ekstruzija intervertebralnog diska (IIVDE)

Ekstruzija hidriranog intervertebralnog diska (HNPE)

Ekstruzija intervertebralnog diska daleko-lateralno (Far - lateral IVDEl

Hansen tip II

\section{Ekstruzija/Protruzija}

Ekstruzija degeneriranog nucleus pulposusa

Ekstruzija
degeneriranog
nucleus pulposusa

Ekstruzija nedegeneriranog nucleus pulposusa

Ekstruzija nedegenriranog nucleus pulposusa

Ekstruzija umjereno degeneriranog nucleus pulposusa

Ekstruzija degeneriranog nucleus pulposusa

Protruzija intervertebralnog diska i djelomična ruptura anulusa fibrosusa

\section{Klinički znaci}

Akutan do sporo progradirajući nastanak, uglavnom hondrodistrofične pasmine pasa (hondroidna degeneracijal

Perakutan/akutan nastanak, česti ozbiljni simptomi; nucleus pulposus dispergiran preko tri i više kralježaka

Perakutan nastanak s traumom; česti ozbiljni klinički simptomi

Perakutan nastanak s traumom; česti ozbiljni klinički simptomi

Perakutan/akutan nastanak, bez boli; najčešće u vratnom dijelu kralježnice

\section{Radikularna bol}

Kroničan, najčešće nehondrodistrofične pasmine pasa; progresivni klinički simptomi, fibroidna degeneracija 


\section{Nativna rendgenografija}

Kod sumnje na bolest međukralježničnog diska najčešće se primarno radi orijentacijska nativna radiografija kralježnice kako bi se utvrdila približna lokalizacija mjesta lezije. Pri procjeni takvih rendgenograma kralježnice bitan je sistematičan i strpljiv pristup koji uključuje promatranje ključnih točaka. Primarno ćemo obratiti pozornost na međukralježnični prostor diska gdje se najčešće vidi suženje ili uklještenost navedenog prostora, sa ili bez promjene oblika ili veličine foramen intervertebrale. Foramen je iduća točka na koju obraćamo pažnju, promatramo promjenu oblika i veličine sjene dvaju superponiranih foramena te pojavu mineralizacije. Ova sjena $u$ fizioloških rendgenograma najčešće nalikuje obliku „konjske glave“, dok bilo kakva promjena implicira problem u tom području. Bitno je pogledati i područje intervertebralnog diska jer moguća mineralizacija može ukazivati na degeneraciju ili biti vezana uz dob psa. Mineralizacija može smanjivati fleksibilnost te otpornost na pritisak diska i time povećavati mogućnost hernijacije intervertebralnog diska. Pri promatranju diskova treba pažljivo pogledati i prebrojiti koliki je broj od njih mineraliziran jer je to prediktivni faktor hernijacije. Što je veći broj mineraliziranih diskova veća je vjerojatnost hernijacije, a i rekurentnost. U prospektivnoj studiji Stigen i sur. (2019.) na 25 pasa jazavčara, korištena je nativna rendgenografija kralježnice pri čemu je zaključeno da je u $68 \%$ slučajeva ekstruzije diskova bila vidljiva kalcifikacija. Primijećeno je pri tome da je osjetljivost rendgenskog snimanja bila $30 \%$ za kalcificirane diskove dok je $70 \%$ bila za ostatke kalcificiranog materijala. Zaključak je da se pri rendgenološkom snimanju ekstrudirani disk treba smatrati kalcificiranim i u slučaju da nema rendgenološki vidljive kalcifikacije.
Hernijacija ponekad može biti vidljiva i u kralježničnom kanalu, pri čemu je čest slučajan nalaz kalcifikacije dure mater kralježnične moždine što se u literaturi naziva i automijelografijom. Nadalje, tijelo kralješka mogu zahvatiti osteoproliferativne promjene koje se očituju bilateralnim koštanim bujanjima tijela kralješka na jednu od strana intervertebralnog diska te se mogu pri tome spajati. Spojeni segment kralježaka tada djeluje na segmente koji ostaju pokretni, dolazi do pojave skleroze na zglobnim površinama i tijelima kralježaka zbog trenja kralježaka jednoga o drugi što može ukazivati na hernijaciju diska zajedno sa suženjem intervertebralnog prostora. Osteoartrotične promjene mogu zahvatiti i zglobne veze processus articularis na kralješcima što može biti i jedan od indikatora hernijacije. Uza sve navedeno, pri degeneraciji diska čest je nalaz i sjene plina što nazivamo fenomenom vakuuma koji se, prema istraživanju Lamb i sur. (2002.) obično javlja u nehondrodistrofičnih pasmina pasa te u $6 \%$ pasa $\mathrm{s}$ hernijacijom intervertebralnoga diska. Iako je metoda nativne rendgenografije najčešće samo orijentacijska, njena točnost je otprilike 51-61 \% (Lamb i sur., 2002.) u određivanju mjesta hernijacije diska stoga ju ne možemo smatrati relevantnom za daljnji plan operacije (Davies i Liebel, 2016.).

\section{Mijelografija}

Mijelografija je metoda slikovne dijagnostike pri kojoj se aplicira pozitivno kontrastno sredstvo na bazi joda $\mathrm{u}$ subarahnoidni prostor kako bi se prikazala kralježnična moždina i pripadajuće strukture. Mijelografija je, donedavno, najčešće slijedila nakon orijentacijske rendgenografije. Indikacije za nju su uključivale: uredan nativni rendgenogram unatoč kliničkim pokazateljima oštećenja kralježnice, nativni rendgenogram koji nije $\mathrm{u}$ korelaciji s mjestom i patologijom 
vidljivom na neurološkom pregledu, nativni rendgenogram s multiplim lezijama, u slučaju potrebe određivanja stupnja i opsega promjena za planiranje kirurške intervencije te kao pomoć $\mathrm{u}$ isključivanju mogućih diferencijalnih dijagnoza (Paithanpagare i sur., 2008.). Prema nekim izvorima iz literature, točnost mijelografije je oko $90 \%$ u pogledu mjesta te $55 \%$ $\mathrm{u}$ pogledu lateralizacije hernijacije diska pri usporedbi s magnetnom rezonancijom (Davies i Liebel, 2016.).

Pri procjeni mijelografskih snimaka kralježnice psa potrebno je procijeniti koji disk pokazuje znakove hernijacije i na koju stranu predmetna lezija lateralizira. U tome su od velike pomoći ortogonalne i kose projekcije koje snimamo (Bos i sur., 2007.). Preporučljivo je i kombinirati metodu mijelografije $s$ fluoroskopijom da bi se povećao dijagnostički doprinos procjeni lezije. Ono što je bitno zamjetiti je tzv. tekalna vrećica, odnosno nakupina materijala ekstrudiranog diska koji može biti sa ili bez sekundarnog krvarenja iz venskog sinusa, a koja se akumulira $\mathrm{u}$ ekstraduralnom prostoru prouzročeći pojavu koju na slikovnom prikazu zovemo defektom punjenja. Takvi defekti punjenja mogu biti i bilateralni i oni su u tom slučaju kraći. No, ako je punjenje produljeno tada je velika mogućnost oticanja kralježnične moždine i mijelomalacije, a ponekad i epiduralnog krvarenja.

Prema Paithanpagare i sur. (2008.) u izvedbi su moguće: cervikalna, lumbalna i lumbosakralna mijelografija.

Pri cervikalnoj se mijelografiji kontrastno sredstvo aplicira $\mathrm{u}$ subarahnoidni prostor na mjestu cisterna magna. Lokalizacija je točnija odredi li se mjesto $u$ medijanoj liniji na pola udaljenosti od protuberantia occipitalis externa i krila atlasa. Može se palpirati dva $m$. rectus capitis te se spinalna igla uvodi između njih ili na opipljivom odvajanju ta dva mišića. Kod lumbalne mijelografije prvo treba locirati processus spinosus šestog lumbalnog kralješka, kranijalno od zamišljene linije kroz krila crijevne kosti. Igla se uvodi kod kranijalnog ruba šestog lumbalnog kralješka te okomito na podužnu os kralježnice i paralelno s površinom stola dok se se osjeti otpor kosti. Tada vrh igle doseže do ventralnog dijela kralježničnog kanala ili do lamine petog lumbalnog kralješka. Pri zadnjem se igla treba malo povući van, no i dalje mora ostati u medijanoj ravnini. Najčešće se pri pozicioniranju igle doseže do ventralnog subarahnoidnog prostora koji je širi, a prolazi kroz dorzalni subarahnoidni prostor bez posljedica za životinju. Pri izvedbi lumbalne mijelografije moguć je i paramedijani pristup kad se igla uvodi lateralno od palpabilnog processus spinosus šestog lumbalnog kralješka i usmjerava kranioventromedijano, dok se u međuzglobni prostor ulazi pod kutem od 45 stupnjeva. Prikaz rendgenograma nakon primijenjene metode lumbalne mijelografije vidljiv je na slici 2. (a, b).

Iako se u literaturi navode samo cervikalna i lumbalna mijelografija, ovdje je zanimljivo da autori ovoga rada predlažu i treću mogućnost, lumbosakralnu mijelografiju, ističući samo njezine prednosti. Njezinim pozitivnim stranama pretpostavljaju: kralježnična moždina završava na kaudalnom dijelu lumbalnog segmenta te je stoga mali rizik za ozljedu moždine, a lakša je za izvedbu zbog većeg prostora. Mjesto punkcije je lako palpabilno i autori dosad nisu zamijetili neurološke simptome, uključujući i napadaje neurološke etiologije, nakon mijelografije. Prednosti mijelografije uključuju: najčešće je prvi izbor (jer omogućuje samostalno izvođenje), omogućuje lokalizaciju patologije te je njome moguće prikupiti uzorak cerebrospinalnog likvora. Postoje i negativne strane ove pretrage: predstavlja invazivnu metodu, životinja se izlaže izvoru ionizirajućeg zračenja, mora se poduzimati opća anestezija, moguće su reakcije na kontrastno 
sredstvo, pogoršanje simptoma te napadaji neurološke etiologije.

Usporedbe radi, $\mathrm{u}$ istraživanju Israel i sur. (2008.) prikazali su osjetljivost kompjuterizirane tomografije (CT-a) i mijelografije za otkrivanje hernijacije diska u 182 psa. Došli su do spoznaje da je osjetljivost mijelografije $83,6 \%$ te da je pogodnija za korištenje kod manjih pasmina pasa (manje od $5 \mathrm{~kg}$ tjelesne mase). Nasuprot tome, kompjuterizirana tomografija je pokazala osjetljivost od $81,8 \%$ za otkrivanje hernijacije diska te
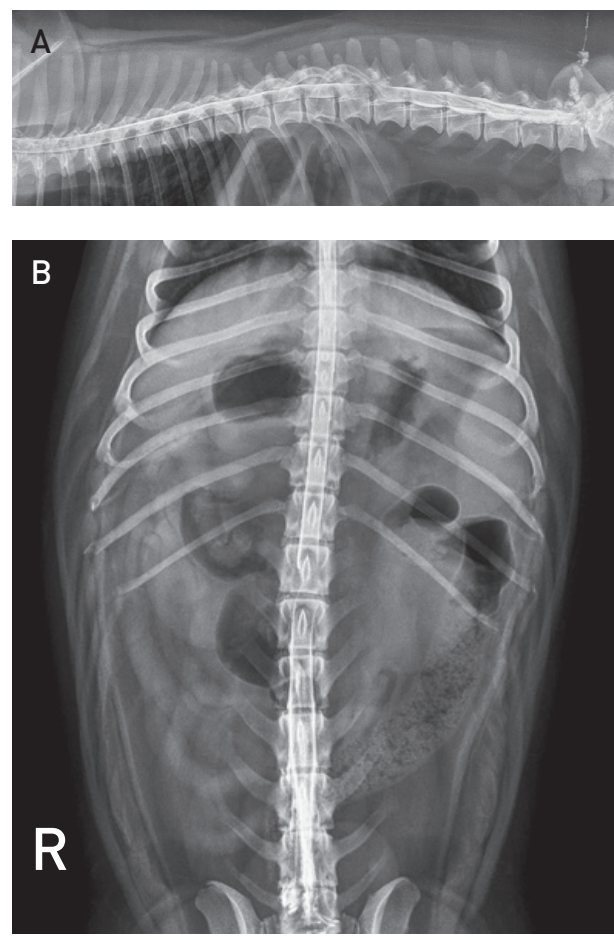

Slika 2. Al Prikaz nalaza mjelografije psa u laterolateralnoj projekciji i Bl u ventrodorzalnoj projekciji. Pozitivno kontrastno sredstvo je aplicirano između zadnjeg lumbalnog kralježka i križne kosti te je vidljiva distribucija duž subarahnoidnog prostora grudnog i slabinskog segmenta kralježnice. U području intervertebralnog prostora prvog i drugog lumbalnog kralježka vidljiv je defekt punjenja koji upućuje na hernijaciju intervertebralnog diska. (Izvor: Arhiva Zavoda za rendgenologiju, ultrazvučnu dijagnostiku i fizikalnu terapiju, Veterinarski fakultet Sveučilišta u Zagrebu) je pogodnija za kronično oboljele psa i pasmine pasa veće tjelesne mase.

\section{Kompjuterizirana tomografija (CT)}

Kompjuterizirana tomografija (CT) je radiološka metoda koja pripada $\mathrm{u}$ suvremenije metode dijagnostike. Nativni CT se obično koristi u prikazivanju promjena u vidu lize kostiju, mineralizacije mekih tkiva ili diskova te prikazu formiranja nove kosti. Ako se nativnim CT-om ne može dovoljno dobro izdiferencirati određene strukture, može se načiniti CT mijelografija. CT mijelografija podrazumijeva primjenu kontrastnog sredstva na bazi joda $s$ koncentracijom koja se smanjuje do 100 $\mathrm{mg} / \mathrm{mL}$ uz fiziološku otopinu kako bi se izbjeglo stvaranje artefakata. Koriste se helikalni kontinuirani presjeci debljine do $3 \mathrm{~mm}$, najčešće $u$ aksijalnoj ravnini. CT je u usporedbi s nativnom rendgenografijom osjetljivija metoda te je korisniji kod snimanja kontrastnim sredstvom jer se linije raspodjele kontrastnog sredstva bolje vizualiziraju ovom metodom. CT $\mathrm{u}$ usporedbi s mijelografijom posjeduje veću brzinu pregleda, nema nuspojava vezanih uz mijelografiju, može prikazati kralježnicu u više ravnina te poboljšava mogućnost otkrivanja lateralizacije hernijacije intervertebralnog diska. Relativna osjetljivost kod korištenja nekontrastnog CT-a pri određivanju mjesta hernijacije intervertebralnog diska je 84 do 100 \% (Newcomb i sur., 2012.), dok je pri određivanju lateralizacije ekstrudiranog diska do $94 \%$. Treba istaknuti zanimljiv podatak da je prema istraživanju Schroeder i sur. (2011.) relativna osjetljivost kontrastnog CT-a za određivanje mjesta i strane hernijacije 97 do $100 \%$, iako nije rađena usporedba s nekontrastnim CT-om. U odnosu na magnetnu rezonanciju (MR) ima određene prednosti u vidu: dostupnosti, bržeg izvođenja snimanja te mogućnosti 
dobivanja multiplanarne rekontrukcije slike područja interesa. Ipak, zamjerke CT-u su: slabija diferencijacija prikaza mekih tkiva (npr. nemineralizirani diskovi) no u to ne ubrajamo krvarenja,

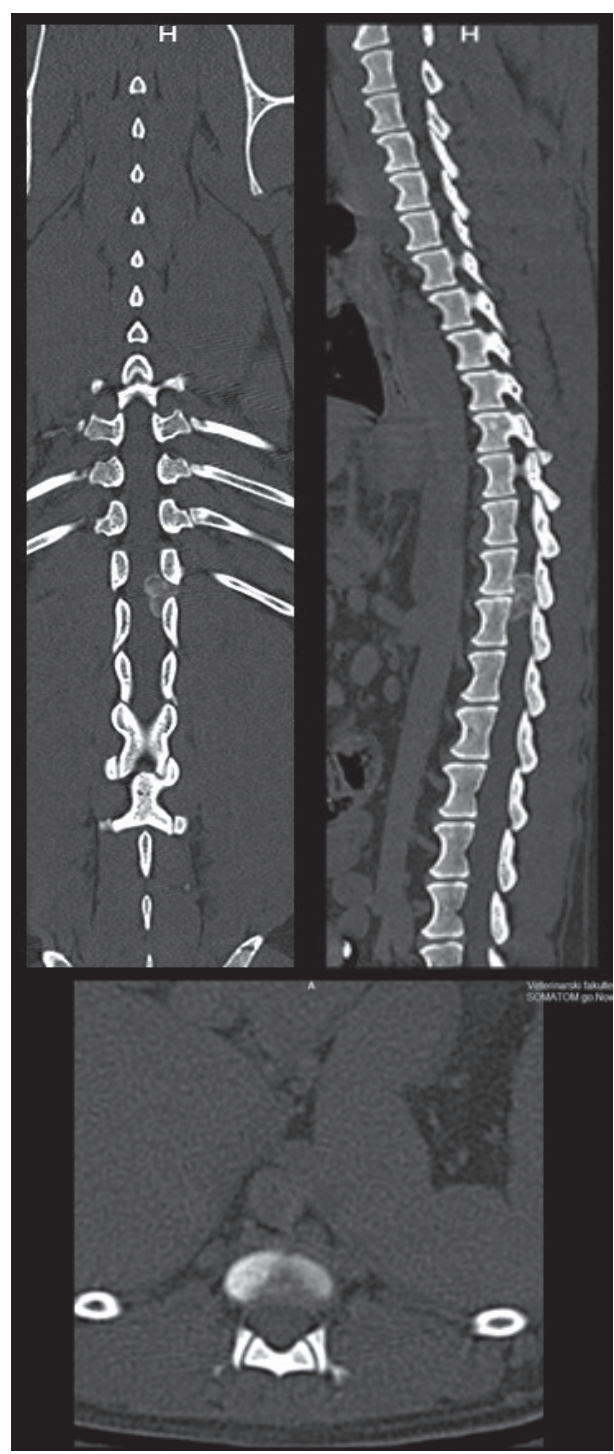

Slika 3. CT prikaz hernijacije intervertebralnog diska u području intervertebralnog prostora prvog i drugog lumbalnog kralježka. (Izvor: Arhiva Zavoda za rendgenologiju, ultrazvučnu dijagnostiku i fizikalnu terapiju, Veterinarski fakultet Sveučilišta u Zagrebu) intramedularne mase i kronične lezije. Izvodimo li snimanje CT-om, najčešće je nativno snimanje dostatno za hondrodistrofične pasmine pasa, budući da je kod njih česta mineralizacija diska te se lako detektira povećanjem Hounsfieldovih jedinica u softveru radne jedinice. Za ostale pasmine pasa predlaže se izvođenje CT mijelografije za što točniji prikaz.

Nalaz na presjecima CT-a u slučaju hernijacije intervertebralnog diska je: gubitak opaciteta epiduralne masti koji okružuju komprimiranu kralježničnu moždinu, vidljiva kompresija kralježnične moždine, materijal mineraliziranog intenziteta sjene $\mathrm{u}$ vertebralnom kanalu i materijal u epiduralnom prostoru sjene koja odgovara krvarenju (Hecht i sur., 2008.).

Prema Stigen i sur. (2019.) u istraživanju na jazavčarima, znanstvenici su došli do zaključka da je osjetljivost CT-a za detekciju kalcificiranog diska u kralježničnom kanalu 100 \%. Preporučili su korištenje CT-a kao dijela protokola za otkrivanje hernijacija intervertebralnog diska u rasplodnom programu pasmine jazavčar skandinavskih zemalja.

U izvođenju CT-a preporuča se primarno napraviti orijentacijsko snimanje (scan) te nakon toga, u slučaju potrebe, pristupiti daljnjoj dijagnostici unutar CT-a (npr. CT mijelografija). Treba imati na umu da su u pasa kroničnih pacijenata, onih koji boluju od kardiovaskularnih ili bubrežnih bolesti te šećerne bolesti, moguće kontrastom prouzročene nefropatije. Na slici 3. vidljiv je CT prikaz hernijacije intervertebralnog diska.

\section{Magnetna rezonancija (MR)}

Magnetna rezonancija (MR) predstavlja najsuvremeniju metodu izbora u slikovnoj dijagnostici kod sumnje na hernijaciju intervertebralnog 
Tabela 2. Degeneracije intervertebralnog diska - stupnjevanje pri magnetnoj rezonanciji (prema Pfirmann i sur., 2001., Bergknut i sur., 2011.).

\begin{tabular}{|c|c|c|c|c|} 
Stupanj & Struktura & $\begin{array}{c}\text { Naličje nucleus } \\
\text { pulposus/ } \\
\text { anulus fibrosus }\end{array}$ & $\begin{array}{c}\text { Signal } \\
\text { cerebrospinalnog } \\
\text { likvora }\end{array}$ & $\begin{array}{c}\text { Širina } \\
\text { intervertebralnog } \\
\text { diska }\end{array}$ \\
\hline 1 & $\begin{array}{r}\text { Homogena }- \\
\text { svijetlo bijela }\end{array}$ & Čisto & $\begin{array}{c}\text { Hiper/ } \\
\text { izointenzivan }\end{array}$ & Normalna \\
\hline 2 & $\begin{array}{c}\text { Heterogena }- \text { sa } \\
\text { ili bez išaranosti }\end{array}$ & Čisto & $\begin{array}{c}\text { Hiper/ } \\
\text { izointenzivan }\end{array}$ & Normalna \\
\hline 3 & Heterogena - siva & Zamućeno & Osrednji & $\begin{array}{c}\text { Normalna do blago } \\
\text { smanjena }\end{array}$ \\
\hline 4 & $\begin{array}{r}\text { Heterogena }- \text { siva } \\
\text { do crna }\end{array}$ & Izgubljeno & $\begin{array}{c}\text { Osrednji/ } \\
\text { hipointenzivan }\end{array}$ & $\begin{array}{c}\text { Normalna do } \\
\text { umjereno smanjena }\end{array}$ \\
\hline 5 & $\begin{array}{r}\text { Heterogena }- \\
\text { crna }\end{array}$ & Izgubljeno & Hipointenzivan & Kolabiran \\
\hline
\end{tabular}

diska. Prema protokolu, najčešće se rade sagitalna i transverzalna projekcija do područja međukralježničnog prostora dorzalno $\mathrm{i}$ ventralno te kranijalno i kaudalno od mjesta hernijacije. Dorzalna projekcija se izvodi da bi se dobilo što točniju lokalizaciju lezije kao pripremu za plan operacije. Ovaj postupak je posebice koristan kod sumnje na patologiju u području grudnoslabinske kralježnice. Pri otkrivanju mjesta i strane lezije kod MR-e možemo se poslužiti i kontrastnim snimanjem. Obzirom da kod hernijacija intervertebralnog diska dolazi do degeneracije diska u ovom slučaju je osmišljen sustav procjene unutar pet stupnjeva degeneracije (Pfirmann i sur., 2001., Bergknut i sur., 2011.) (Tabela 2). U slučajevima kad je na snimcima MR vidljiva hernijacija intervertebralnog diska i epiduralno krvarenje, treba posumnjati na lokalizaciju u kaudalnom dijelu lumbalne kralježnice kao predilekcijskom mjestu za navedena stanja. MR, u odnosu na druge metode slikovne dijagnostike, omogućava i vizualizaciju multiplih lezija, koje mogu biti akutne ili kronične te po tome predstavlja i određenu prednost nad ostalim slikovnim metodama. Na slikama 4. i 5. vidljiv je primjer MR-e prikaza stupnjevanja hernijacije i degeneracije intervertebralnog diska po Pfirmann-u na cervikalnom segmentu kralježnice.

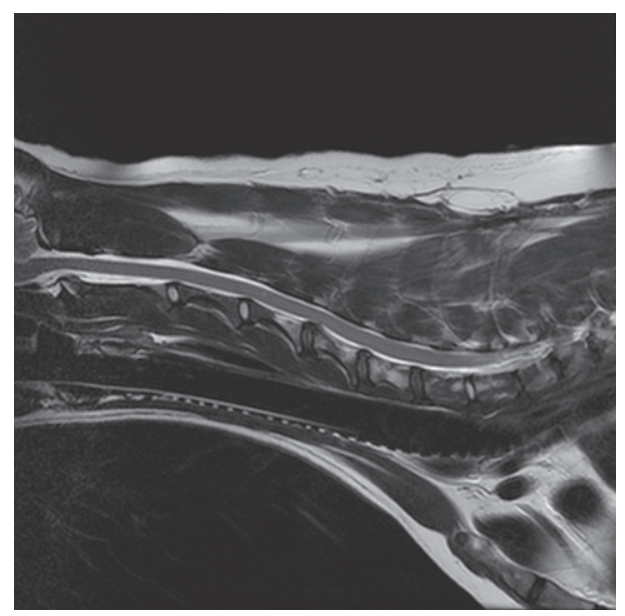

Slika 4. Midsagitalna T2-ponderirana slika MR-e cervikalnog dijela kralježnice psa. Nema vidljivih tragova degeneracije intervertebralnog diska u području C2-C3 i C3-C4 (Pfirmann stupanj 1). Intervertebralni disk u području C7-T1 je nehomogen, s hiperintenzivnim bijelim signalom (Pfirmann stupanj 2). Intervertebralni diskovi u području C4-C5, C5-C6 te C6-C7 pokazuju znakove degeneracije, nehomogeni su i pokazuju nehomogeni intermitetni sivi signal (Pfirmann stupanj 3). (Slike dostupne ljubaznošću Dario Nappo, dr. med. vet., Istituto Veterinario di Novara - AniCura Italy Novara) 


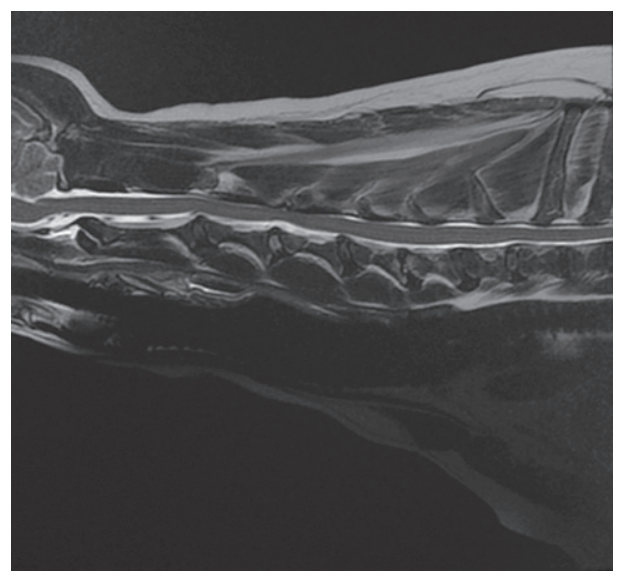

Slika 5. Midsagitalni T2-ponderirani prikaz MR-om cervikalnog dijela kralježnice psa. Intervertebralni disk u području C6-C7 je nehomogen $s$ hipointenzivnim tamnosivim signalom (Pfirmann stupanj 4). Intervertebralni disk u području C5-C6 je hipointenzivan s tamnim signalom te je kolabiranog prostora diska. Islike dostupne ljubaznošću Dario Nappo, dr. med. vet., Istituto Veterinario di Novara - AniCura Italy Novara)

Reynolds i sur. (2012.) uspoređivali su dijagnostičku točnost MR-e u odnosu na mijelografiju i $u$ odnosu na kirurški zahvat. Uzeli su u obzir 10 pasa $\mathrm{s}$ rekurentnim hernijacijama intervertebralnog diska kojima je rađena minihemilaminektomija. Istraživanje je pokazalo veću točnost MR-e u lokalizaciji hernijacije $u$ odnosu na mijelografiju ili kirurški zahvat. Pri tome su rekurentnim hernijacijama intervertebralnog diska smatrali stanja u slučajevima kad se hernijacija ponovno pojavila 8 do 14 mjeseci nakon operacije. Rekurentne lezije češće su bile do prostora hernijacije diska ili jedan prostor dalje od inicijalne lezije. $U$ dijagnostici navedenog stanja koristili su MR dijagnostiku u području od devetog torakalnog kralješka do križne kosti. Prednosti MR u odnosu na mijelografiju, koje su u tom istraživanju navedene su: postizanje boljeg kontrasta, snimanje koje nije ograničeno superpozicijom struktura te točnija lokalizacija lezije. Sto se tiče CT-e i MR-e, autori su u svome istraživanju preporučili da se ove metode slikovne dijagnostike koriste u slučajevima ranije pojave rekurentnosti hernijacija jer su omogućavale bolju lokalizaciju kompresivnog materijala u kanalu kralježnične moždine. Njihov je zaključak kako je MR bolja za određivanje novih i starih lezija te je $\mathrm{u}$ određivanju mjesta i strane na koju se prikazuje rekurentna lezija hernijacije intervertebralnog diska u malih pasmina pasa točnija.

Kod tumačenja snimaka MR-e treba pripaziti na pojavu kontrastnog pojačanja koje se može pojaviti u do 50 \% slučajeva (Davies i Liebel, 2016.) posebno često ako su u pitanju slučajevi ekstruzije diska te u subakutnim ili kroničnim slučajevima. Prema novim smjernicama dobro je napraviti kontrolno snimanje MR-om nakon operacije, no treba imati na umu da je moguća vizualizacija artefakata u području interesa u vidu krvarenja od operacije, mikroskopskih fragmenata te ostataka paramagnetičnih materijala za šivanje koji tada ometaju signal i otežavaju diferencijaciju u predmetnom području promatranja.

Ono što se ponekad može vidjeti u slučajevima hernijacije intervertebralnog diska na prikazu MR-e su i tzv. ciste diska. One nastaju zbog degeneracije intervertebralnog diska, tekućina unutar njih je hiperintenzivne sjene, dok okolno epiduralno masno tkivo i cerebrospinalna tekućina mogu „maskirati“ hernijaciju, a ovaj uzorak $\mathrm{u}$ transverzalnom presjeku vidimo kao "sliku galeba u letu“.

Tip hernijacije koji je posebno pogodan za snimanje MR-om je tzv. akutna nekompresivna (traumatska) hernijacija nucleus pulposus intervertebralnog diska (ANNPE). Ovu hernijaciju odlikuje prikaz na MR-u koji obuhvaća: kolaps intervertebralnog prostora, smanjen volumen nucleus pulposus, kontuziju kralježnične moždine dok nema značajnije kompresije kralježnične moždine. Promatrajući snimak MR-e primjećujemo dobro definiran asimetrični 
intramedularni hiperintenzitet sjene dorzalno od diska na transverzalnom prikazu. Pasmine pasa koje najčešće zahvaća navedena hernijacija diska su graničarski koli, bul-terijeri i labrador retrieveri, dok dobna predispozicija ne postoji (Davies i Liebel, 2016.).

\section{Zaključak}

Hernijacije intervertebralnog diska su patološka stanja koje je moguće dijagnosticirati pomoću metoda slikovne dijagnostike kao što su: CT, MR i mijelografija, dok se metodom nativne rendgenografije može postaviti isključivo sumnja. Prema dosad dostupnim istraživanjima, najprihvatljivijom se metodom pokazala MR koja omogućuje sigurnu dijagnostiku i lokalizaciju u 100 \% slučajeva, dok su za ostale metode postotci uspjeha detekcije manji. Treba uzeti u obzir da se korištenje određene metode slikovne dijagnostike $u$ lokalizaciji i lateralizaciji mjesta hernijacije intervertebralnog diska u svakodnevnoj praksi najčešće prilagođava financijskim mogućnostima vlasnika, dostupnosti određene metode i žurnosti postupka. Shodno tome, rezultati pretraga variraju kao i točnost lokalizacije hernijacije.

\section{Literatura}

1. BALTZER, W. I., L. HILLEBRAND, T. J. SMITH and S. M. STIEGER-VANEGAS (2012): Surgical management of a Schmorl's node in an Airdaile Terrier and review of the literature. Vet. Comp. Orthop. Traumatol. 25, 167-171. 10.3415/VCOT-1106-0088

2. BELTRAM, E., R. DENNIS, V. DOYLE, A. DE STEFANI, A. HOLLOWAY and L. DE RISIO (2012): Clinical and magnetic resonance imaging features of canine compressive cervical myelopathy with suspected hydrated nucleus pulposus extrusion. J. Small Anim. Pract. 53, 101-117. 10.1111/j.17485827.2011.01166.x

3. BERGKNUT, N., E. AURIEMMA, S. WIJSMAN, G. VOORHOUT, R. HAGMAN, A.-S. LAGERSTEDT, H. A. W. HAZEWINKEL and B. P. MEIJ (2011): Evaluation of intervertebral disk degeneration in chondrodystrophic and nonchondrodystrophic dogs by use of Pfirrmann grading of images obtained with low-field magnetic resonance imaging. Am. J. Vet. Res. 72, 893-898. 10.2460/ ajvr.72.7.893

4. BOS, A. S., B. A. BRISSON, D. L. HOLMBERG and S. G. NYKAMP (2007): Use of the ventrodorsal myelographic view to predict lateralization of extruded disk material in small breed dogs with thoracolumbar intervertebral disk extrusion: 104 cases (2004-2005). J. Am. Vet. Med. Assoc. 230, 18601865. 10.2460/javma.230.12.1860

5. DAVIES, J. V. and F.-X. LIEBEL (2016): Spine - intervertebral disc disease and 'Wobbler syndrome'. In: BSAVA Manual of Canine and Feline Musculoskeletal Imaging (Kirberger R. M., F. J. McEvoy, Eds.), $2^{\text {nd }}$ Ed., BSAVA, Gloucester.

6. FADDA, A., J. LANG and F. FORTERRE (2013): Far lateral lumbar disc extrusion: MRI findings and surgical treatment. Vet. Comp. Orthop. Traumatol. 26, 318-322. 10.3415/VCOT-12-08-0106

7. FUNKQUIST, B. (1962): Thoraco-lumbar disk protrusion with severe cord compression in the dog. 1. Clinical and pathoanatomic observations with special reference to the rate of development of the symptoms of motor loss. Acta. Vet. Scand. 3, 256-274. 10.1186/BF03547144

8. FUNKQUIST, B. (1970): Decompressive laminectomy in thoraco-lumbar disc protrusion with paraplegia in the dog. J. Small Anim. Pract. 11, 445-451. 10.1111/j.1748-5827.1970.tb05595.x

9. GASCHEN, L., J. LANG and H. HÄNI (1995): Intravertebral disk herniation (Schmorl'node) in five dogs. Vet. Radiol. Ultrasound 36, 509-516. 10.1111/j.1740-8261.1995.tb00304.x

10. HANSEN, H. J. (1952): A pathological study on disc degeneration in dog. Acta Orto. Scand. Suppl. no XI., 117. 10.3109/ort.1952

11. HEBLINSKI, N. and H. SCHMÖKEL (2018): Our approach to intervertebral disc disease in dogs: a review of the current literature. J. Vet. Sci. Med. Diagn. 7,1. 10.4172/2325-9590.1000246

12. HECHT, S., W. B. THOMAS, K. MARIONIHENRY, R. L. ECHANDI, A. R. MATTHEWS and W. H. ADAMS (2009): Myelography vs. computed tomography in the evaluation of acute thoracolumbar intervertebral disk extrusion in chondrodystrophic dogs. Vet. Radiol. Ultrasound 50, 353-359. 10.1111/j.1740-8261.2009.01549.x

13. HENKE, D., D. GORGAS, T. FLEGEL, M. VANDEVELDE, J. LANG, M. G. DOHERR and F. FORTERRE (2013): Magnetic resonance imaging findings in dogs with traumatic intervertebral disk extrusion with or without spinal cord compression: 31 cases (2006-2010). J. Am. Vet. Med. Assoc. 242, 217-222. 10.2460/javma.242.2.217

14. ISRAEL, S. K., J. M. LEVINE, S. C. KERWIN, G. J. LEVINE and G. T. FOSGATE (2009): The relative sensitivity of computed tomography and myelography for identification of thoracolumbar intervertebral disk herniations in dogs. Vet. Radiol. Ultrasound 50, 247-252. 10.1111/j.17408261.2009.01528.x 
15. LAMB, C. R., A. NICHOLLS, M. TARGETT and P. MANNION (2002): Accuracy of survey radiographic diagnosis of intervertebral disc protrusion in dogs. Vet. Radiol. Ultrasound 43, 222228. 10.1111/j.1740-8261.2002.tb00994.x

16. NEWCOMB, B., J. ARBLE, M. ROCHAT, R. PECHMAN and M. PAYTON (2011): Comparison of computed tomography and myelography to a reference standard of computed tomographic myelography for evaluation of dogs with intervertebral disc disease. Vet. Surg. 41, 207-214. 10.1111/j.1532-950X.2011.00911.x.

17. OLSON, S. E. (1951): On disc protrusion in dog (enchodrosis intervertebralis); a study with special reference to roentgen diagnosis and to the value of disc fenestration. Acta Orto. Scand. Suppl. 8, 95. 10.3109/ort.1951.22.suppl-8.01

18. PAITHANPAGARE, Y. M., P. H. TANK, M. Y. MANKAD, K. SHIRODKAR and H. J. DERASHRI (2008): Myelography in dogs. Vet. World 1, 152-154.

19. PFIRMANN, C. W. A., A. METZDORF, M. ZANETTI, J. HODLER and N. BOOS (2001):
Magnetic resonance classification of lumbar intervertebral disc degeneration. Spine 26, 18731878. 10.1097/00007632-200109010-00011

20. REYNOLDS D., B. A. BRISSON and S. G. NYKAMP (2013): Agreement between magnetic resonance imaging, myelography, and surgery for detecting recurrent, thoracolumbar intervertebral disc extrusion in dogs. Vet. Comp. Orthop. Traumatol. 26, 12-18. 10.3415/VCOT-12-05-0067

21. SCHROEDER, R., D. H. PELSUE, R. D. PARK, D. GASSO and K. A. BRUECKER (2011): Contrast-enhanced CT for localizing compressive thoracolumbar intervertebral disc extrusion. J. Am. Anim. Hosp. Assoc. 47, 203-209. 10.5326/JAAHAMS-5550

22. STIGEN, Ø., T. CIASCA and Ø. KOLBJØRNSEN (2019): Calcification of extruded intervertebral discs in dachshunds: a radiographic, computed tomographic and histopathological study of 25 cases. Acta Vet. Scand. 61, 13. 10.1186/s13028-019$0448-2$

\section{Comparison of diagnostic imaging methods for intervertebral disc herniation in dogs}

Tomislav BUREŠ, DVM, Assistant, Hrvoje CAPAK, DVM, PhD, Assistant Professor, Branimir ŠKRLIN, DVM, Expert Associate, Dino STANIN, DVM, Expert Associate, Anita KRALJEVIĆ, Postgraduate Master Student, Faculty of Veterinary Medicine, University of Zagreb, Croatia, Dario NAPPO, Istituto Veterinario di Novara - AniCura Italy Novara, Italy; Zoran VRBANAC, DVM, PhD, Associate Professor, DECVSMR, DACVSMR, Department of Radiology, Ultrasound Diagnostic and Physical Therapy, Faculty of Veterinary Medicine, University of Zagreb, Croatia

Intervertebral disc herniation is a common disorder of the intervertebral disc. There are many causes of this condition: disc degeneration, trauma, infection, or anatomical/developmental abnormalities. In the diagnosis of herniation, various methods of diagnostic imaging can be applied, such as: survey radiography, myelography, computed tomography or magnetic resonance imaging. According to the literature, the most reliable method has proven to be magnetic resonance imaging, which allows for a sound diagnosis and localization in $100 \%$ of cases, while the success rates of detection for other methods are lower. It should be noted that the use of a particular imaging method in the localization and lateralization of the herniation site of the intervertebral disc in everyday practice is usually guided by the financial capacities of the owner, the availability of a particular method, and the urgency of the procedure. Consequently, the test results vary and thus the accuracy of the herniation localization. The aim of this review article is to show the specifics of intervertebral disc herniation and the methods for the most accurate diagnosis using imaging methods available in everyday veterinary practice.

Key words: diagnostic imaging; intervertebral disc; herniation; dog 